\title{
The Relationship between Platelet Count and Host Gut Microbiota: A Population-Based Retrospective Cross-Sectional Study
}

\author{
Hee-Young Yoon ${ }^{1,+}{ }^{\dagger}$ Han-Na Kim ${ }^{2, \dagger}$, Su Hwan Lee ${ }^{3}$, Soo Jung Kim ${ }^{1}{ }^{1}$, Yoosoo Chang ${ }^{4,5}$, \\ Seungho Ryu ${ }^{4,5}$ (D) Hocheol Shin ${ }^{6}$, Hyung-Lae Kim ${ }^{7, * \mathbb{D}}$ and Jin Hwa Lee ${ }^{1, * \mathbb{D}}$ \\ 1 Department of Internal Medicine, College of Medicine, Ewha Womans University, Seoul 07804, Korea; \\ bluecat-s@hanmail.net (H.-Y.Y.); crystalkim38@gmail.com (S.J.K.) \\ 2 Medical Research Institute, Kangbuk Samsung Hospital, Sungkyunkwan University, School of Medicine, \\ Seoul 03181, Korea; hanna147942@gmail.com \\ 3 Division of Pulmonology, Department of Internal Medicine, Institute of Chest Diseases, Severance Hospital, \\ Yonsei University College of Medicine, Seoul 03722, Korea; hihogogo@naver.com \\ 4 Center for Cohort Studies, Total Healthcare Center, Kangbuk Samsung Hospital, Sungkyunkwan University, \\ School of Medicine, Seoul 04514, Korea; yoosoo.chang@samsung.com (Y.C.); sh703.yoo@samsung.com (S.R.) \\ 5 Department of Occupational and Environmental Medicine, Kangbuk Samsung Hospital, \\ Sungkyunkwan University, School of Medicine, Seoul 03181, Korea \\ 6 Department of Family Medicine, Kangbuk Samsung Hospital, Sungkyunkwan University School of \\ Medicine, Seoul 03181, Korea; hcfm.shin@samsung.com \\ 7 Department of Biochemistry, College of Medicine, Ewha Womans University, Seoul 07804, Korea \\ * Correspondence: hyung@ewha.ac.kr (H.-L.K.); jinhwalee@ewha.ac.kr (J.H.L.); \\ Tel.: +82-2-6986-6202 (H.-L.K.); +82-2-6986-1631 (J.H.L.) \\ + These authors contributed equally to this paper.
}

Received: 13 December 2018; Accepted: 7 February 2019; Published: 10 February 2019

\begin{abstract}
Platelet count reflects the severity and prognosis of multiple diseases. Additionally, alterations in gut microbiota have been linked to several chronic diseases. The purpose of this study was to investigate the association between gut microbiota and platelet count. We selected 1268 subjects with fecal 16S RNA gene sequencing data from a Healthcare Screening Center cohort. Based on the third quartile of platelets $\left(277 \times 10^{9} / \mathrm{L}\right)$, we compared the gut microbiota between the upper quartile $(n=321)$ and lower three quartiles groups $(n=947)$. The upper quartile group had lower alpha diversity based on observed amplicon sequence variants $(q=0.004)$ and phylogenetic index $(q<0.001)$ than the lower three quartiles group. Significant differences were also found in the weighted UniFrac distance $(q=0.001)$ and Jaccard dissimilarity $(q=0.047)$ beta diversity measures between the two groups. Compared with the lower three quartiles group, the upper quartile group exhibited decreased relative abundances of the genus Faecalibacterium, which was also inversely correlated with the platelet count. Increased platelet count was associated with reduced diversity in gut microbiota and lower abundances of Faecalibacterium with beneficial gut bacteria spices F. prausnitzii, suggesting that an increased platelet count, even within normal range, may adversely affect gut microbial diversity and composition.
\end{abstract}

Keywords: gut microbiota; 16S RNA; platelet; thrombocytosis; Faecalibacterium

\section{Introduction}

Humans consistently interact with their microbiota, which is defined as the collection of microorganisms living inside and on the human body. The bacteria of the microbiota and their genomes are collectively referred to as the microbiome [1,2]. The human gut contains the greatest 
number and density of bacteria in the human body, and its microbiota is host-specific based on heritable components [3] and is modified by acquired factors such as diet, drugs, surgery, and aging [4-7]. The gut microbiota plays important roles in the development and progression of numerous medical conditions, including obesity [8], inflammatory bowel disease (IBD) [9], cardiovascular disease [10,11], and neurodegenerative diseases [12]. The recent terms "gut-brain axis" and "gut-lung axis" indicate that gut microbiota can influence multiple organs and systems by producing metabolites and chemicals, and causing the release of inflammatory cytokines $[13,14]$.

Thrombocytosis is mainly derived from secondary causes with the exception of essential thrombocytosis, which is due to clonal thrombopoiesis. Not only acute conditions such as infection, inflammation, and blood loss, but also chronic conditions (e.g., iron deficiency, chronic inflammatory or infectious diseases, malignancy) contribute to reactive thrombocytosis [15]. In addition, platelets regulate the immune system by releasing pro-inflammatory factors and activating innate immunity [16]. Although thrombocytosis has been demonstrated to predict the prognosis of several pathologic conditions [17-20], the impact of relative increases in platelet count within the normal limit on the human body remains unclear. Because the gut microbiota is a sensitive marker of several diseases, reflecting an individual's immune system and inflammatory status, we hypothesized that small changes in platelet count might lead to changes in the gut microbiome.

We previously demonstrated that the neutrophil-to-lymphocyte ratio and inflammatory markers were associated with the gut microbiome in a Korean population [21]. Here, we aimed to evaluate the association between the gut microbiota and platelet count in a Korean population using health screening data.

\section{Materials and Method}

\subsection{Study Population}

We screened 1463 Korean men and women between 25 and 78 years old who visited Kangbuk Samsung Hospital Healthcare Screening Center in the Republic of Korea for a comprehensive annual or biennial physical examination from June to September 2014 (Figure 1).

Total 1,463 subjects with $16 \mathrm{~S}$ rRNA sequencing from fecal DNA

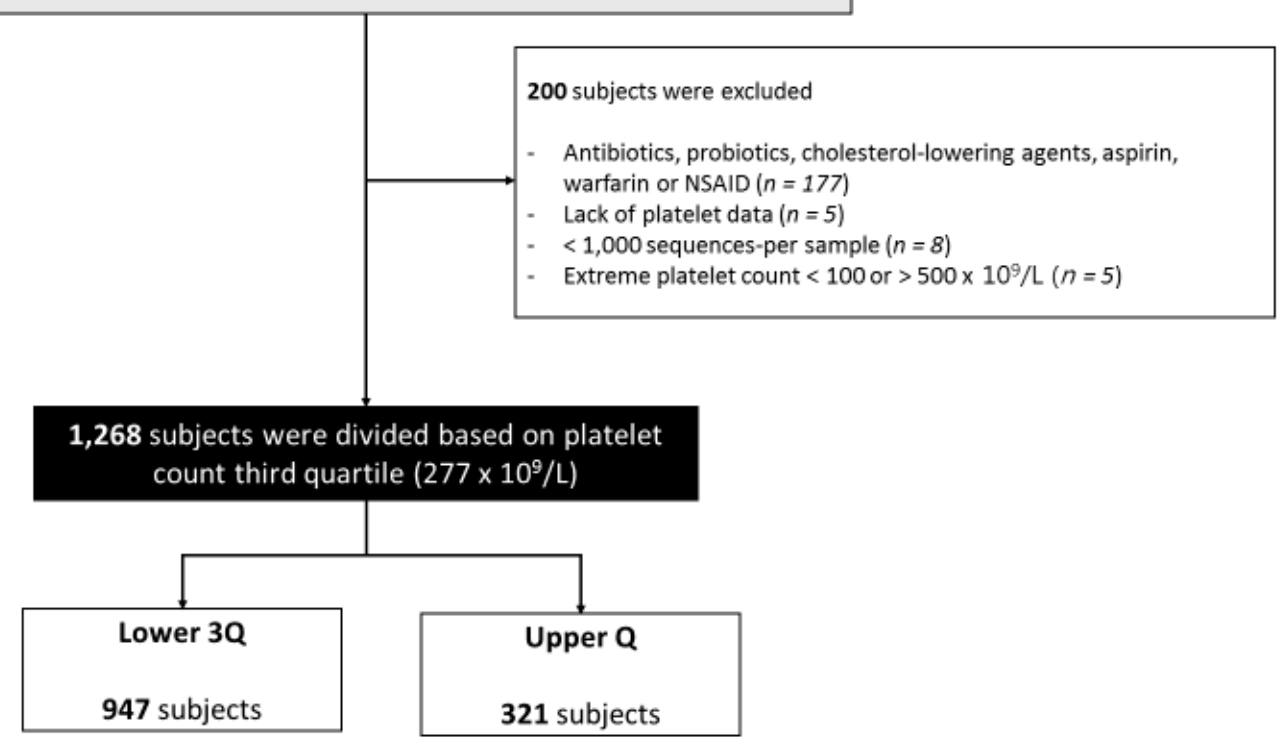

Figure 1. Flowchart of subjects' enrollment. NSAID, non-steroidal anti-inflammatory drugs; Lower 3Q, $<75$ th percentile for platelet count; Upper $Q, \geq 75$ th percentile for platelet count. 
Among 1463 subjects with fecal DNA samples for 16S rRNA sequencing, 195 subjects were excluded for the following reasons: medications that could affect the gut microbiome and/or platelet function $(n=182)$, lack of baseline platelet count $(n=5)$, or less than 1,000 sequences per sample $(n=8)$. Additionally, five subjects were excluded because their platelets were not within the newly devised reference range (between 100 and $500 \times 10^{9} / \mathrm{L}$ ) based on the distribution of platelet counts excluding outliers. Finally, 1268 subjects were included in our study.

\subsection{Study Design}

We assessed correlations between platelet count and the relative abundances of gut microbiota. Our subjects were divided into two groups, the lower three quartiles $(3 Q ; n=947)$ and the upper quartile $(n=321)$ based on third quartile platelet count $\left(3 \mathrm{Q}=277 \times 10^{9} / \mathrm{L}\right)$. The diversity and composition of the gut microbiota were compared between the upper $\mathrm{Q}$ and lower $3 \mathrm{Q}$ groups. Because the normal range of platelet count varies by sex [22,23], subgroup analysis was performed using the third quartile platelet count according to sex (268 $\times 10^{9} / \mathrm{L}$ for men and $294 \times 10^{9} / \mathrm{L}$ for women).

Demographic data, laboratory findings, and medical and diet histories were retrospectively reviewed through medical records and questionnaires taken at the time of sample collection. This study was approved by the Institutional Review Board of Kangbuk Samsung Hospital (KBSMC 2013-01-245-12) and written informed consent was provided by all subjects.

\subsection{DNA Extraction and $16 S$ Gene rRNA Sequencing for Bacterial Communities}

Fresh fecal samples were obtained immediately after defecation and stored at $-70{ }^{\circ} \mathrm{C}$ within $24 \mathrm{~h}$ until DNA extraction. Genomic DNA was extracted using the MO Bio PowerSoil ${ }^{\circledR}$ DNA Isolation Kit (MO BIO Laboratories, Carlsbad, CA, USA) in accordance with the manufacturer's instructions. The methods used to amplify and sequence the DNA were detailed in our previous study [24]. Briefly, the universal primers $341 \mathrm{~F}$ and $805 \mathrm{R}$ were used to amplify genomic DNA in the variable V3 and V4 regions of the 16S rRNA genes. The $16 \mathrm{~S}$ rRNA sequencing of all samples was performed with the read length of $300 \mathrm{bp}$ paired-end using the Illumina MiSeq platform (Illumina, San Diego, CA, USA) with the manufacturer's specifications [25].

\subsection{Compositional Analysis of $16 S$ rRNA Gene}

The sequence quality control and feature table construction were performed using DADA2 [26] of QIIME2 plugins (version 2018.08, https:/ / qiime2.org) [27,28]. Low quality sequences and chimeric sequences were excluded. The amplicon sequence variants (ASVs) were produced by denoising with DADA2 and regarded as 100\% operational taxonomic units (OTUs) [29]. After denoising, the paired-sequences were merged and, after that, the chimeras were removed. We created the feature table, including the abundance table and the representational sequence file. The taxonomic classification was performed using a pre-trained Naïve Bayes classifier and the q2-feature-classifier plugin. This classifier was trained on the V3-V4 region containing the gene from $99 \%$ OTUs files in the Greengenes 13_8 release of $16 \mathrm{~S}$ rRNA gene sequences [30].

\subsection{Statistical Analysis}

All continuous variables were presented as mean \pm standard deviation (SD) and categorical variables were expressed as number (\%). QIIME2 (version 2018.08) was used to analyze the diversity and composition of gut microbiota between groups [29]. Before diversity analyses, the feature tables were rarefied with 1000 sample depth evenly by random subsampling. Alpha diversity indices, which measures the number of distinct ASVs in each sample, was expressed using the actual number of different taxa observed in a sample as the non-phylogenetic index ("Observed ASVs") and a phylogenetic diversity (PD) measurement, Faith's PD, which incorporated phylogenetic difference between ASVs [31]. Alpha diversity was also measured using the following two non-phylogenetic methods: the Shannon index, which is measured by accounting for both evenness and 
richness [32], and the Pielou's evenness, which quantifies how equal the community is numerically [33]. The difference in alpha diversity between groups was calculated using the Kruskal-Wallis test. The beta diversity between groups was assessed using with following three methods: unweighted UniFrac distance as phylogenetic and qualitative index; weighted UniFrac distance as phylogenetic and quantitative index for abundance differences [34]; Jaccard dissimilarity as non-phylogenetic and qualitive index for presence/absence differences [35]. Differences in beta diversity between platelet groups was compared using pairwise permutational multivariate analysis of variance (PERMANOVA with 999 permutations) [36]. For composition analysis, taxa with low abundance (less than 10\%) were filtered. Analysis of composition of microbiome (ANCOM) in QIIME2 was used to compare the log-ratio different abundances of gut microbial taxa in the upper and lower 3Q groups [37]. The correlation between the abundance of taxa and platelet count and comparison of the abundance of taxa between the upper and lower $3 \mathrm{Q}$ groups were assessed using multivariate association with linear models (MaAsLin, version 1.0.1, http:/ / huttenhower.sph.harvard.edu/maaslin) software package [38] for R (version 3.5.1, URL http: / / www.R-project.org). Analyses included covariate adjustments for age, sex, smoking status, and body mass index (BMI), all of which could affect gut microbiome composition [39-42]. All analyses using MaAsLin were performed with the default settings and presented as covariate-adjusted coefficients (CE). The differentially abundant taxa between the two groups at different taxonomy levels were presented as W-statistics.

Additionally, microbial community function was evaluated by predictive metagenome (microbial DNA) analysis using PICRUSt (Phylogenetic Investigation of Communities by Reconstruction of Unobserved States) [43]. PICRUSt is a developed phylogeny-based computational tool that predicts the functional capacity of microbial communities by correlating the species present to reference databases of microbial genomes. We performed PICRUSt with de-novo variants according to a recent manual (https:/ / github.com/LangilleLab/microbiome_helper/wiki/PICRUSt-Tutorialwith-de-novo-Variants). DADA2 variants were normalized using the 16S rRNA copy number, and KEGG (Kyoto Encyclopedia of Genes and Genomes) orthologs (KOs) were predicted. Results that aggregated to level three of the KEGG analysis module were further explored with STAMP (statistical analysis of taxonomic and functional profiles) version 2.1.3 [44], using two-group analysis module. The resulting $p$-values were corrected for multiple comparisons on the number of pathways using FDR (Benjamini-Hochberg, $q$-value).

\section{Results}

\subsection{Baseline Characteristics}

Of the total 1268 subjects (mean age: 45.4 years, men: 62.1\%), 947 and 321 subjects were classified into the lower $3 \mathrm{Q}$ and upper $\mathrm{Q}$ groups, respectively (Table 1).

Table 1. Baseline demographics and laboratory findings between the upper and lower 3 quartiles groups.

\begin{tabular}{ccccc}
\hline Variables & Lower 3Q & Upper Q & Total & $p$-Value \\
\hline No. & 947 & 321 & 1268 & \\
Age, years & $45.7 \pm 9.0$ & $44.7 \pm 8.4$ & $45.4 \pm 8.8$ & 0.093 \\
Male sex & $634(66.9 \%)$ & $153(47.7 \%)$ & $787(62.1 \%)$ & $<0.001$ \\
Body mass index, $\mathrm{kg} / \mathrm{m}^{2}$ & $23.6 \pm 3.1$ & $23.6 \pm 3.1$ & $23.6 \pm 3.1$ & 0.748 \\
Smoking status & & & & 0.056 \\
Never & $505(57.0 \%)$ & $195(64.8 \%)$ & $700(59.0 \%)$ & \\
Former & $216(24.4 \%)$ & $58(19.3 \%)$ & $274(23.1 \%)$ & \\
Current & $165(18.6 \%)$ & $48(15.9 \%)$ & $213(17.9 \%)$ & \\
Smoking amount, pack-years & $14.4 \pm 10.8$ & $15.4 \pm 13.9$ & $14.6 \pm 11.6$ & 0.483 \\
\hline
\end{tabular}


Table 1. Cont.

\begin{tabular}{ccccc}
\hline Variables & Lower 3Q & Upper Q & Total & $p$-Value \\
\hline Laboratory finding & & & & \\
Platelet, $10^{9} / \mathrm{L}$ & $224.4 \pm 33.5$ & $314.9 \pm 36.4$ & $247.3 \pm 52.2$ & $<0.001$ \\
White blood cell, $10^{3} / \mathrm{mm}^{3}$ & $5.6 \pm 1.4$ & $6.4 \pm 1.6$ & $5.8 \pm 1.5$ & $<0.001$ \\
Neutrophil, \% & $54.9 \pm 8.0$ & $56.0 \pm 7.7$ & $55.2 \pm 8.0$ & 0.037 \\
Lymphocyte, \% & $33.5 \pm 7.4$ & $34.9 \pm 7.1$ & $35.4 \pm 7.3$ & 0.167 \\
Eosinophil, \% & $2.6 \pm 2.1$ & $2.4 \pm 1.9$ & $2.6 \pm 2.4$ & 0.189 \\
Basophil, \% & $0.4 \pm 0.3$ & $0.5 \pm 0.3$ & $0.5 \pm 0.3$ & 0.003 \\
Monocyte, \% & $6.5 \pm 1.6$ & $6.2 \pm 1.5$ & $6.4 \pm 1.6$ & 0.003 \\
Neutrophil/lymphocyte ratio & $1.7 \pm 0.7$ & $1.7 \pm 0.6$ & $1.7 \pm 0.7$ & 0.238 \\
Hematocrit, \% & $42.3 \pm 3.6$ & $40.9 \pm 4.0$ & $42.0 \pm 3.7$ & $<0.001$ \\
Iron, $\mu \mathrm{g} / \mathrm{dL}$ & $122.0 \pm 41.4$ & $115.5 \pm 4.5 .6$ & $120.4 \pm 42.6$ & 0.045 \\
Ferritin, ng/mL & $161.1 \pm 135.1$ & $138.0 \pm 128.3$ & $155.3 \pm 133.7$ & 0.008 \\
C-reactive protein, $\mathrm{mg} / \mathrm{dL}$ & $0.1 \pm 0.2$ & $0.1 \pm 0.1$ & $0.1 \pm 0.2$ & 0.808 \\
\hline
\end{tabular}

Data are presented as mean (standard deviation) or number (\%). Lower $3 \mathrm{Q},<75$ th percentile for platelet count; Upper $Q, \geq 75$ th percentile for platelet count.

The upper $\mathrm{Q}$ group had fewer men than the lower $3 \mathrm{Q}$ group. Additionally, the upper $\mathrm{Q}$ group had more total white blood cells (WBCs), neutrophils, and basophils, but lower levels of monocytes, hematocrit, serum iron, and ferritin compared to the lower $3 \mathrm{Q}$ group. There were no significant differences in comorbidities or nutritional status between the two groups (Supplementary Tables S1 and S2).

Because the sex distribution between the two groups was different, we performed sub-group analyses according to sex using sex-specific third quartiles of platelet count $\left(268 \times 10^{9} / \mathrm{L}\right.$ for men and $294 \times 10^{9} / \mathrm{L}$ for women). In men, WBC and basophil counts were significantly different between the lower 3Q $(n=589)$ and upper $Q(n=198)$ groups (Supplementary Table S3). In women, the upper $Q$ group $(n=121)$ had a higher BMI, higher levels of WBC and basophils, and lower levels of hematocrit, serum iron, and ferritin compared with the lower $3 \mathrm{Q}$ group $(n=360)$.

\subsection{Comparison of Alpha Diversity between the Upper Quartile and Lower Three Quartiles Groups}

The upper $Q$ group had significantly lower alpha diversity measurements including observed ASVs $(q=0.004), \operatorname{PD}(q<0.001)$ and Shannon index $(q=0.002)$ compared to the lower 3Q group (Figure 2). However, the evenness was not significantly different between the two groups $(q=0.254)$.
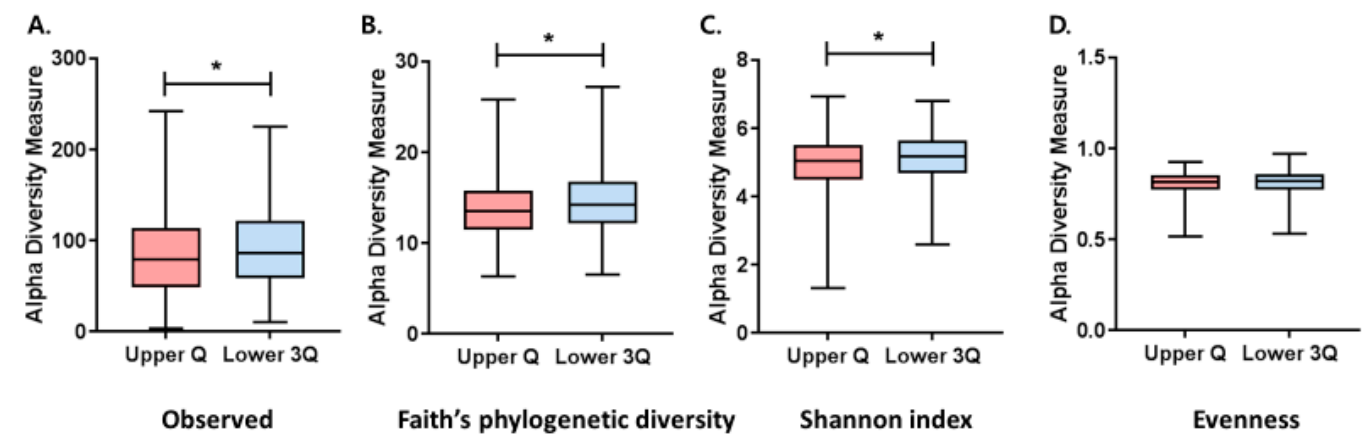

Figure 2. Comparison of alpha diversity indexes between the upper and lower three quartiles groups. (A) Observed amplicon sequence variants (ASVs), (B) phylogenetic diversity, (C) Pielou evenness, and (D) Shannon's index. Lower $3 \mathrm{Q},<75$ th percentile for platelet count; Upper $Q, \geq 75$ th percentile for platelet count. ${ }^{*} q<0.05$.

Subgroup analyses of men showed that alpha diversity in the upper Q group as measured by observed ASVs $(q=0.048)$, PD $(q=0.007)$, and the Shannon index $(q=0.009)$ was also lower than in the lower 3Q groups (Supplementary Figure S1). Additionally, the evenness between the two groups 
approached significance $(q=0.078)$. In contrast, in women, no significant differences in alpha diversity between the two groups were observed (Supplementary Figure S2).

\subsection{Comparison of Beta Diversity between the Upper Quartile and Lower Three Quartiles Groups}

Significant differences in beta diversity between the upper $Q$ and lower $3 Q$ groups were identified as measured by unweighted UniFrac distance $(q=0.001)$ and Jaccard dissimilarity $(q=0.017)$, but not by weighted UniFrac analysis ( $q=0.156$; Table 2 and Supplementary Figure S3).

Table 2. The statistical significances of beta diversity distances from lower three quartiles groups based on different measurement methods.

\begin{tabular}{cccc}
\hline Beta Diversity Indices & Total & Male & Female \\
\hline Unweighted UniFrac distance & $3.472 *$ & $2.964 *$ & 1.598 \\
Weighted UniFrac distance & 1.696 & $3.074 *$ & 1.643 \\
Jaccard dissimilarity & $1.299 *$ & 1.167 & 1.059 \\
\hline The values are presented with the pseudo-F statistic from 999 permutation. ${ }^{*} q<0.05$.
\end{tabular}

Subgroup analyses of men showed that beta diversity measured by unweighted $(q=0.003)$ and weighted UniFrac distance $(q=0.020)$ was also significantly different between the two groups (Supplementary Figure S4), and the difference in beta diversity based on Jaccard dissimilarity approached statistical significance $(q=0.076)$. In contrast, the beta diversity measurements between the upper $\mathrm{Q}$ and lower $3 \mathrm{Q}$ groups were similar in women, with only a trend toward significance for the unweighted UniFrac distance ( $q=0.052$; Supplementary Figure S5).

\subsection{Comparison of the Microbial Composition between the Upper Quartile and Lower Three Quartile Groups}

Significant differences in relative abundances between the upper $Q$ and lower $3 \mathrm{Q}$ groups were assessed from phylum to species level using the ANCOM method (Table 3). The upper Q group had significantly reduced abundance of Clostridia class, Clostridiales order, Ruminococcaceae family, and Faecalibacterium genus compared to the lower $3 \mathrm{Q}$ group. The $\mathrm{W}$ is interpreted as follows: the " $\mathrm{W}=10$ " of Clostridia indicates that the class was detected to be significantly different relative to 10 other classes between the two groups.

Table 3. The comparison of microbiome composition between the upper and lower three quartiles groups.

\begin{tabular}{|c|c|c|c|}
\hline Level & Taxonomic Assignment & $\mathbf{W}^{\mathbf{a}}$ & Normalized $\mathrm{W}^{\mathrm{b}}$ \\
\hline Class & 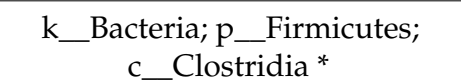 & 10 & 0.32 \\
\hline Order & $\begin{array}{c}\text { k_Bacteria; p_Firmicutes; } \\
\text { c_Clostridia; o__Clostridiales * } \\
\text { k__Bacteria; p__Firmicutes; }\end{array}$ & 21 & 0.44 \\
\hline Family & c_Clostridia; o__Clostridiales; & 34 & 0.40 \\
\hline Genus & $\begin{array}{l}\text { k_Bacteria; } \text { p_Firmicutes; } \\
\text { c_Clostridia; o__Clostridiales; } \\
\text { f__Ruminococcaceae; } \\
\text { g__Faecalibacterium * }\end{array}$ & 140 & 0.65 \\
\hline
\end{tabular}

* Decreased in the upper group. $\mathrm{k}$, kingdom; $\mathrm{p}$, phylum; c, class; o, order; $\mathrm{f}$, family; $\mathrm{g}$, genus; ${ }^{\mathrm{a}}$ if $\mathrm{W}=\mathrm{X}$ for taxon $\mathrm{k}$, then $\mathrm{H}_{0 \mathrm{k}}$ is rejected $\mathrm{X}$ times. The $\mathrm{W}$ statistic for a significant difference in taxa relative to other taxa at each taxa level is represented; ${ }^{\mathrm{b}} \mathrm{W}$ statistics are normalized with each total taxa number (W statistic/total taxa number (class: 31, order: 48 , family: 85 , genus: 214$)$ ).

Among men, no significant differences in the relative abundances of taxa between the upper $\mathrm{Q}$ and lower $3 \mathrm{Q}$ were identified. However, the upper $\mathrm{Q}$ group in women showed a remarkably decreased 
abundance of the Ruminococcaceae family and Faecalibacterium genus compared to the lower 3Q group (Supplementary Table S4). In contrast, the Chloroplas class and Aeromonadales order was increased in the female upper $Q$ group, while the Mollicutes class was decreased in the female upper $Q$ group compared with the female lower $3 \mathrm{Q}$ group.

\subsection{Correlation between Platelet Count and Gut Microbiota}

Based on a MaAsLine analyses adjusted for age, sex, smoking status, BMI, total WBC count, and hematocrit in all subjects, the relative abundance of several bacteria decreased as the platelet count increased (Table 4). The platelet count negatively correlated with the genera Faecalibacterium (CE: $-0.00022, q=0.0016)$.

Table 4. The correlation between identified taxa and platelet count on MaAsLin analysis.

\begin{tabular}{ccccccc}
\hline \multirow{2}{*}{ Order } & Family & Genus & $\begin{array}{c}\boldsymbol{n} \text { Not to } \\
\text { Zero (\%) }\end{array}$ & CE & $\boldsymbol{p}$-Value * & $\boldsymbol{q}$-Value * \\
\hline Clostridiales & Ruminococcaceae & & 1257 & -0.00031 & 0.00043 & 0.0064 \\
Clostridiales & Ruminococcaceae & Faecalibacterium & 1220 & -0.00022 & 0.00097 & 0.0016 \\
\hline
\end{tabular}

CE, coefficient. * Adjusted for age, sex, body mass index, smoking status, total white blood cell count, and hematocrit.

The regression $\mathrm{CE}$ represents the rate of change in abundance of taxa per $10^{9} / \mathrm{L}$ platelets.

\subsection{Comparison of the Functional Microbial Composition between the Upper Quartile and Lower Three Quartiles Groups}

We compared functional profiles generated by PICRUSt between the upper $Q$ and the lower $3 Q$ groups. The predicted functions of the gut microbiota in the upper $\mathrm{Q}$ and lower $3 \mathrm{Q}$ groups were similar based on KEGG ortholog composition, with only subtle statistical differences observed based on unadjusted $p$-values. Based on level two profile analysis, PICRUSt predicted a higher abundance of genes in the 'Infectious diseases' KEGG pathway in the upper Q group compared to the lower 3Q group. Based on level three profile analysis, genes related to the 'Nitrogen metabolism' pathway were highly enriched in the upper $Q$ group, while the pathway related to "Glycosphingolipid biosynthesis-lacto and neolacto series" was enriched in the lower 3Q group.

Subgroup analysis of men only indicated that in the lower $3 \mathrm{Q}$ group, there were very subtle increases in the genes involved in the 'Glycosphingolipid biosynthesis-lacto and neolacto series' pathway that were significant following adjustment compared with the upper group (difference: $4.50 \times 10^{-7}, 95 \%$ confidential interval: $2.22 \times 10^{-7}$ to $6.78 \times 10^{-7}$, adjusted $p=0.038$; Supplementary Figure S6). Among women, we found that several pathways related to the immune system, infectious diseases, and energy metabolism were higher in the upper $Q$ group than in the lower $3 Q$ groups; however, these differences were only supported by unadjusted $p$-values.

\section{Discussion}

This large cohort study demonstrated that increased platelet count was associated with decreased diversity of the gut microbiota in a Korean population. The gut microbiota composition also changed according to platelet level. In particular, there was a negative correlation between platelet count and genus Faecalibacterium. In subgroup analyses according to sex, diversity was significantly different between the upper $Q$ and lower $3 \mathrm{Q}$ groups in men, whereas only differences in composition were observed between the two groups in women. Comparative analysis of functional composition revealed some differences between the two groups, but these differences were not statistically significant.

In this study, platelet count was inversely correlated with the relative abundance of Faecalibacterium prausnitzii; the sole known species of Faecalibacterium is one of the major butyrate producers of gut microbiota [45]. Among short-chain fatty acids (SCFAs), microbiota-induced fermentation products such as butyrate are a main energy source for colonocytes and can promote a healthy gut through anti-inflammatory action [46]. F. prausnitzii plays a beneficial role in the 
intestine by secreting butyrate with unidentified metabolites [47]. Furthermore, because its abundance is reduced in several intestinal diseases, including IBD and colon cancer [47,48], F. prausnitzii has potential as a biomarker for gut health. It is possible that the association between F. prausnitzii and platelets may be the reason that platelet count is associated with IBD prognosis [49]. Interestingly, elevated platelet counts are related to prognosis in diabetic patients [50,51], in whom the abundance of F. prausnitzii is lower compared with non-diabetic patients and inversely correlated with inflammatory markers such as interleukin-6 (IL-6) and hs-CRP [52]. Given the association between platelet count and several diseases in which the abundance of $F$. prausnitzii correlates with prognosis or disease severity, platelet count might be suppressed by the anti-inflammatory activity of $F$. prausnitzii [46]. Consistent with this, a decrease in IL-6, which promotes platelet production [53], was observed after treatment with F. prausnitzii in a mouse model [54].

Our study demonstrated that the alpha diversity in the upper $Q$ group was reduced compared with the lower $3 \mathrm{Q}$ group. This finding suggests that the composition of the gut microbiota might be affected by platelet count and/or could contribute to thrombocytosis. Reduced diversity of the gut microbiota often leads to outgrowth of a few species and decreased resilience, which can be unhealthy $[55,56]$. Several chronic diseases including obesity, IBD, diabetes, and atopic eczema, with increased prevalence in recent decades have been linked to low diversity of the gut microbiota [1,57-59]. In addition, low gut microbiome diversity is associated with increased mortality in some clinical conditions such as allogenic hematopoietic stem cell transplantation and graft-versus-host disease $[60,61]$. Taken together, increased platelet count could represent a reduction in gut diversity.

According to our results, expression of genes related to the 'Glycospingolipid biosynidesis-lacto and neolacto series' pathway was increased in the male lower $3 Q$ group compared with the male upper Q group. Glycospingolipids (GSLs) are a subtype of glycolipids found in the cell membrane of human and bacterial cells that comprise a ceramide backbone covalently bonded to a glycan moiety. GSL biosynthesis is a stepwise process, characterized by first adding sugars to ceramides followed by glycan growth [62]. Among GSLs during this synthesis process, GM1 [63], GD1a, GD1b, and GT1b [64] suppress platelet-derived growth factor (PDGF)-dependent cell growth and receptor tyrosine phosphorylation. PDGF, which is released from platelets, stimulates the proliferation of megakaryocytes in vitro [65], while PDGF knockout leads to thrombocytopenia in mouse embryos [66]. Furthermore, there are several clinical conditions related to thrombocytosis as well as essential thrombocythemia that lead to increased PDGF levels [67-70]. Overall, gut microbiota might induce thrombocytosis by generating GSLs that inhibit PDGF activity.

Although a normal platelet count generally ranges from 150 to $450 \times 10^{9} / \mathrm{L}$ [71], there are sex-specific differences in normal platelet count. Specifically, women have a slightly higher platelet count than men [23]. In our study, the greater number of women in the upper $Q$ group was attributed to the higher third quartile value in women than in men ( 294 [women] vs. $268 \times 10^{9} / \mathrm{L}$ [men]). This imbalanced gender distribution also resulted in differences in hematocrit, iron, and ferritin between the upper $Q$ and lower $Q$ groups because the women in our study were mostly young, healthy, premenopausal women with potential iron deficiency anemia (IDA). In IDA women, platelet counts are inversely correlated with hematocrit and iron [72,73], which supports our findings. However, these factors are unlikely to have significantly impacted our results because the microbial diversity differences between the upper and lower groups were only found in men and all subjects and not in women. The lack of statistical differences in women could be attributed to the relatively small number of subjects. Compositional differences between the two groups were noticeable in women, possibly due to the wider distribution of platelets (mean \pm SD: $261.2 \pm 56.2$ (women) vs. $238.8 \pm 47.6 \times 10^{9} / \mathrm{L}$ (men), $p<0.001$ ). Therefore, in women, the extreme distributional differences in platelet counts may have contributed to the significant differences observed in the composition of the microbiota.

Our study had several limitations. First, this was a single center, cross-sectional retrospective study without longitudinal follow-up data. Therefore, we could not determine whether platelet 
changes or gut microbiome changes occurred first. However, we assumed that gut microbiome affects platelet count through microbial functional pathway analysis. Second, our study was conducted on a relatively healthy population and therefore did not include patients with thrombocytosis meeting the common definition $\left(>500 \times 10^{9} / \mathrm{L}\right)$. We only demonstrated that a relative elevation of platelets within normal range was linked to a potentially characteristic gut environment. To investigate the association between the gut microbiome and thrombocytosis, further studies are required. Third, we identified the quantitative association between platelet count and the gut microbiome but did not confirm any qualitative association. Since platelets are functionally independent from their count [74], subjects with platelet function defects might have influenced the results of our study. To reduce this possibility, subjects receiving medications that would affect platelet function were excluded from our study. Lastly, the baseline characteristics between the upper $Q$ and lower 3Q groups were not identical; in particular, gender distribution was varied. Those differences might have affected gut microbiome analyses. Therefore, we analyzed the diversity and composition of the gut microbiome separately in men and women. Linear correlation was also adjusted by sex, age, BMI, smoking status, WBC count, and hematocrit to control for any additional confounders.

\section{Conclusions}

In summary, the diversity and composition of the gut microbiome in patients with increased platelet counts were distinct from those with lower platelet counts. The genus Faecalibacterium, which contains the species F. prausnitzii with beneficial effects on gut, was negatively correlated with platelet count, potentially due to its anti-inflammatory function. Overall, we firstly report an association between gut microbiota and platelet count, which suggests that gut microbiota might influence platelet count systemically. Thus, platelet count could be a biomarker for detecting changes in gut microbiota, even in populations with platelet counts within relatively normal range. Additional studies are needed to confirm the antecedent association and mechanism between platelets and gut microbiota

Supplementary Materials: The following are available online at http:/ /www.mdpi.com/2077-0383/8/2/230/s1, Table S1: Comparison of commodities between the upper and lower three quartile groups, Table S2: Comparison of nutritional status between the upper and lower three quartile groups, Table S3: Comparison of baseline demographics and laboratory findings between the upper and lower three quartile groups within males and females, Table S4: The comparison of microbiome composition between the upper and lower three quartile groups in females, Figure S1: Comparison of alpha diversity indexes between the upper and lower three quartile groups in the males, Figure S2: Comparison of alpha diversity indexes between the upper and lower three quartile groups in the females, Figure S3: Prediction of metagenome functional content correlated with platelet count using PICRUSt, Figure S4: Beta diversity distances from the lower three quartile groups using different measurement methods in the whole subjects population, Figure S5: Beta diversity distances from the lower three quartile groups using different measurement methods in males, Figure S6: Beta diversity distances from the lower three quartile groups using different measurement methods in females.

Author Contributions: Conceptualization, H.-L.K. and J.H.L.; data curation, H.-Y.Y.; formal analysis, H.-Y.Y.; funding acquisition, H.-L.K. and J.H.L.; investigation, H.-N.K.; methodology, H.-Y.Y. and H.-N.K.; resources, Y.C., S.R., and H.S.; software, H.-Y.Y.; supervision, S.H.L., S.J.K., Y.C., S.R., H.S., H.-L.K., and J.H.L.; writing-original draft, H.-Y.Y. and J.H.L.; writing-review and editing, H.-Y.Y., H.-N.K., S.H.L., S.J.K., and J.H.L.

Funding: This research was supported by the Basic Science Research Program through the National Research Foundation of Korea (NRF) and funded by the Ministry of Science and ICT (NRF-2018R1D1A1B07050067) and by the Medical Research Funds from Kangbuk Samsung Hospital. The study was also supported by an NRF grant funded by the Korean government (MSIT) (2010-0027945).

Acknowledgments: We are thankful for the computing resources provided by the Global Science experimental Data hub Center (GSDC) Project and the Korea Research Environment Open NETwork (KREONET) at the Korea Institute of Science and Technology Information (KISTI).

Conflicts of Interest: The authors have no conflicts of interest to declare. The funders had no role in the design of the study; in the collection, analyses, or interpretation of data; in the writing of the manuscript, or in the decision to publish the results. 


\section{References}

1. Schloss, P.D.; Westcott, S.L.; Ryabin, T.; Hall, J.R.; Hartmann, M.; Hollister, E.B.; Lesniewski, R.A.; Oakley, B.B.; Parks, D.H.; Robinson, C.J.; et al. Introducing mothur: Open-Source, Platform-Independent, Community-Supported Software for Describing and Comparing Microbial Communities. Appl. Environ. Microbiol. 2009, 75, 7537-7541. [CrossRef] [PubMed]

2. Gill, S.R.; Pop, M.; DeBoy, R.T.; Eckburg, P.B.; Turnbaugh, P.J.; Samuel, B.S.; Gordon, J.I.; Relman, D.A.; Fraser-Liggett, C.M.; Nelson, K.E.; et al. Metagenomic Analysis of the Human Distal Gut Microbiome. Science 2006, 312, 1355-1359. [CrossRef] [PubMed]

3. Goodrich, J.K.; Waters, J.L.; Poole, A.C.; Sutter, J.L.; Koren, O.; Blekhman, R.; Beaumont, M.; Van Treuren, W.; Knight, R.; Bell, J.T.; et al. Human Genetics Shape the Gut Microbiome. Cell 2014, 159, 789-799. [CrossRef] [PubMed]

4. Wu, G.D.; Chen, J.; Hoffmann, C.; Bittinger, K.; Chen, Y.-Y.; Keilbaugh, S.A.; Bewtra, M.; Knights, D.; Walters, W.A.; Knight, R.; et al. Linking Long-Term Dietary Patterns with Gut Microbial Enterotypes. Science 2011, 334, 105-108. [CrossRef] [PubMed]

5. Preidis, G.A.; Versalovic, J. Targeting the Human Microbiome with Antibiotics, Probiotics, and Prebiotics: Gastroenterology Enters the Metagenomics Era. Gastroenterology 2009, 136, 2015-2031. [CrossRef] [PubMed]

6. Rogers, M.A.M.; Aronoff, D. The influence of non-steroidal anti-inflammatory drugs on the gut microbiome. Clin. Microbiol. Infect. 2016, 22, 178.e1-178.e9. [CrossRef]

7. Woodmansey, E.J. Intestinal bacteria and ageing. J. Appl. Microbiol. 2007, 102, 1178-1186. [CrossRef]

8. Turnbaugh, P.J.; Ley, R.E.; Mahowald, M.A.; Magrini, V.; Mardis, E.R.; Gordon, J.I. An obesity-associated gut microbiome with increased capacity for energy harvest. Nature 2006, 444, 1027-1031. [CrossRef]

9. Hold, G.L. Role of the gut microbiota in inflammatory bowel disease pathogenesis: What have we learnt in the past 10 years? World J. Gastroenterol. 2014, 20, 1192. [CrossRef]

10. Tang, W.H.W.; Hazen, S.L. The Gut Microbiome and Its Role in Cardiovascular Diseases. Circulation 2017, 135, 1008-1010. [CrossRef]

11. Holmes, E.; Loo, R.L.; Stamler, J.; Bictash, M.; Yap, I.K.S.; Chan, Q.; Ebbels, T.; De Iorio, M.; Brown, I.J.; Veselkov, K.A.; et al. Human metabolic phenotype diversity and its association with diet and blood pressure. Nature 2008, 453, 396-400. [CrossRef] [PubMed]

12. Quigley, E.M.M. Microbiota-Brain-Gut Axis and Neurodegenerative Diseases. Curr. Neurol. Neurosci. Rep. 2017, 17, 94. [CrossRef] [PubMed]

13. De Vadder, F.; Kovatcheva-Datchary, P.; Goncalves, D.; Vinera, J.; Zitoun, C.; Duchampt, A.; Bäckhed, F.; Mithieux, G. Microbiota-Generated Metabolites Promote Metabolic Benefits via Gut-Brain Neural Circuits. Cell 2014, 156, 84-96. [CrossRef] [PubMed]

14. Fiebiger, U.; Bereswill, S.; Heimesaat, M.M. Dissecting the interplay between intestinal microbiota and host immunity in health and disease: Lessons learned from germfree and gnotobiotic animal models. Eur. J. Microbiol. Immunol. 2016, 6, 253-271. [CrossRef] [PubMed]

15. Schafer, A.I. Thrombocytosis. N. Engl. J. Med. 2004, 350, 1211-1219. [CrossRef] [PubMed]

16. Ali, R.A.; Wuescher, L.M.; Worth, R.G. Platelets: Essential components of the immune system. Curr. Trends Immunol. 2015, 16, 65-78. [PubMed]

17. Słabuszewska-Jóźwiak, A.; Dmoch-Gajzlerska, E.; Kozakiewicz, B.; Jakiel, G. The prognostic significance of thrombocytosis in ovarian cancer. Ann. Agric. Environ. Med. 2015, 22, 731-735. [CrossRef]

18. Mirsaeidi, M.; Peyrani, P.; Aliberti, S.; Filardo, G.; Bordon, J.; Blasi, F.; Ramirez, J.A. Thrombocytopenia and Thrombocytosis at Time of Hospitalization Predict Mortality in Patients With Community-Acquired Pneumonia. Chest 2010, 137, 416-420. [CrossRef]

19. Tomita, M.; Shimizu, T.; Hara, M.; Ayabe, T.; Onitsuka, T. Prognostic impact of thrombocytosis in resectable non-small cell lung cancer. Interact. CardioVasc. Thorac. Surg. 2008, 7, 613-615. [CrossRef]

20. Harrison, M.T.; Short, P.; Williamson, P.A.; Singanayagam, A.; Chalmers, J.D.; Schembri, S. Thrombocytosis is associated with increased short and long term mortality after exacerbation of chronic obstructive pulmonary disease: a role for antiplatelet therapy? Thorax 2014, 69, 609-615. [CrossRef]

21. Yoon, H.-Y.; Kim, H.-N.; Lee, S.H.; Kim, S.J.; Chang, Y.; Ryu, S.; Shin, H.; Kim, H.-L.; Lee, J.H. Association between Neutrophil-to-Lymphocyte Ratio and Gut Microbiota in a Large Population: A Retrospective Cross-Sectional Study. Sci. Rep. 2018, 8, 16031. [CrossRef] [PubMed] 
22. Eidelman, O.; Jozwik, C.; Huang, W.; Srivastava, M.; Rothwell, S.W.; Jacobowitz, D.M.; Ji, X.; Zhang, X.; Guggino, W.; Wright, J.; et al. Gender Dependence for a Subset of the Low-Abundance Signaling Proteome in Human Platelets. Hum. Genom. Proteomics 2010, 2, 1-14. [CrossRef] [PubMed]

23. Biino, G.; Santimone, I.; Minelli, C.; Sorice, R.; Frongia, B.; Traglia, M.; Ulivi, S.; Di Castelnuovo, A.; Gögele, M.; Nutile, T.; et al. Age- and Sex-Related Variations in Platelet Count in Italy: A Proposal of Reference Ranges Based on 40987 Subjects' Data. PLoS ONE 2013, 8, e54289. [CrossRef] [PubMed]

24. Kim, H.-N.; Yun, Y.; Ryu, S.; Chang, Y.; Kwon, M.-J.; Cho, J.; Shin, H.; Kim, H.-L. Correlation between gut microbiota and personality in adults: A cross-sectional study. Brain Behav. Immun. 2018, 69, 374-385. [CrossRef] [PubMed]

25. Kozich, J.J.; Westcott, S.L.; Baxter, N.T.; Highlander, S.K.; Schloss, P.D. Development of a Dual-Index Sequencing Strategy and Curation Pipeline for Analyzing Amplicon Sequence Data on the MiSeq Illumina Sequencing Platform. Appl. Environ. Microbiol. 2013, 79, 5112-5120. [CrossRef] [PubMed]

26. Callahan, B.J.; McMurdie, P.J.; Rosen, M.J.; Han, A.W.; A Johnson, A.J.; Holmes, S.P. DADA2: High-resolution sample inference from Illumina amplicon data. Nat. Methods 2016, 13, 581-583. [CrossRef] [PubMed]

27. Callahan, B.J.; McMurdie, P.J.; Holmes, S.P. Exact sequence variants should replace operational taxonomic units in marker-gene data analysis. ISME J. 2017, 11, 2639-2643. [CrossRef] [PubMed]

28. Caporaso, J.G.; Kuczynski, J.; Stombaugh, J.; Bittinger, K.; Bushman, F.D.; Costello, E.K.; Fierer, N.; Peña, A.G.; Goodrich, J.K.; Gordon, J.I.; et al. QIIME allows analysis of high-throughput community sequencing data. Nat. Methods 2010, 7, 335-336. [CrossRef] [PubMed]

29. Bolyen, E.; Rideout, J.R.; Dillon, M.R.; Bokulich, N.A.; Abnet, C.; Al-Ghalith, G.A.; Alexander, H.; Alm, E.J.; Arumugam, M.; Asnicar, F.; et al. QIIME 2: Reproducible, Interactive, Scalable, and Extensible Microbiome Data Science. Available online: https:/ / peerj.com/preprints/27295/ (accessed on 13 December 2018).

30. DeSantis, T.Z.; Hugenholtz, P.; Larsen, N.; Rojas, M.; Brodie, E.L.; Keller, K.; Huber, T.; Dalevi, D.; Hu, P.; Andersen, G.L.; et al. Greengenes, a Chimera-Checked 16S rRNA Gene Database and Workbench Compatible with ARB. Appl. Environ. Microbiol. 2006, 72, 5069-5072. [CrossRef] [PubMed]

31. Faith, D.P. Conservation evaluation and phylogenetic diversity. Biol. Conserv. 1992, 61, 1-10. [CrossRef]

32. Neisser, U. Cognitive Psychology: Classic Edition; Psychology Press: New York, NY, USA, 2014.

33. Pielou, E. The measurement of diversity in different types of biological collections. J. Theor. Biol. 1966, 13, 131-144. [CrossRef]

34. Lozupone, C.; Lladser, M.E.; Knights, D.; Stombaugh, J.; Knight, R. UniFrac: An effective distance metric for microbial community comparison. ISME J. 2010, 5, 169-172. [CrossRef] [PubMed]

35. Charbonneau, M.; Subramanian, S.; Seedorf, H.; Knight, R.; Rosenbaum, M.; Faith, J.J.; Guruge, J.L.; Goodman, A.L.; Clemente, J.C.; Heath, A.C.; et al. The long-term stability of the human gut microbiota. Science 2013, 341, 1237439.

36. Navas-Molina, J.A.; Peralta-Sánchez, J.M.; González, A.; McMurdie, P.J.; Vázquez-Baeza, Y.; Xu, Z.; Ursell, L.K.; Lauber, C.; Zhou, H.; Song, S.J.; et al. Advancing Our Understanding of the Human Microbiome Using QIIME. Meth. Enzymol. 2013, 531, 371-444. [PubMed]

37. Mandal, S.; Van Treuren, W.; White, R.A.; Eggesbø, M.; Knight, R.; Peddada, S.D. Analysis of composition of microbiomes: A novel method for studying microbial composition. Microb. Ecol. Health Dis. 2015, 26, 27663. [CrossRef] [PubMed]

38. Lee, S.-W.; Kuan, C.-S.; Wu, L.S.-H.; Weng, J.T.-Y. Metagenome and Metatranscriptome Profiling of Moderate and Severe COPD Sputum in Taiwanese Han Males. PLoS ONE 2016, 11, e0159066. [CrossRef]

39. Odamaki, T.; Kato, K.; Sugahara, H.; Hashikura, N.; Takahashi, S.; Xiao, J.-Z.; Abe, F.; Osawa, R. Age-related changes in gut microbiota composition from newborn to centenarian: A cross-sectional study. BMC Microbiol. 2016, 16, 333. [CrossRef] [PubMed]

40. Markle, J.G.M.; Frank, D.N.; Mortin-Toth, S.; Robertson, C.; Feazel, L.M.; Rolle-Kampczyk, U.; Von Bergen, M.; McCoy, K.D.; MacPherson, A.J.; Danska, J.S.; et al. Sex Differences in the Gut Microbiome Drive Hormone-Dependent Regulation of Autoimmunity. Science 2013, 339, 1084-1088. [CrossRef] [PubMed]

41. Tilg, H.; Moschen, A.R.; Kaser, A. Obesity and the Microbiota. Gastroenterology 2009, 136, 1476-1483. [CrossRef] [PubMed]

42. Savin, Z.; Kivity, S.; Yonath, H.; Yehuda, S. Smoking and the intestinal microbiome. Arch. Microbiol. 2018, 200, 677-684. [CrossRef] [PubMed] 
43. Langille, M.G.I.; Zaneveld, J.; Caporaso, J.G.; McDonald, D.; Knights, D.; A Reyes, J.; Clemente, J.C.; E Burkepile, D.; Thurber, R.L.V.; Knight, R.; et al. Predictive functional profiling of microbial communities using 16S rRNA marker gene sequences. Nat. Biotechnol. 2013, 31, 814-821. [CrossRef] [PubMed]

44. Parks, D.H.; Tyson, G.W.; Hugenholtz, P.; Beiko, R.G. STAMP: Statistical analysis of taxonomic and functional profiles. Bioinformatics 2014, 30, 3123-3124. [CrossRef]

45. Barcenilla, A.; Pryde, S.E.; Martin, J.C.; Duncan, S.H.; Stewart, C.S.; Henderson, C.; Flint, H.J. Phylogenetic Relationships of Butyrate-Producing Bacteria from the Human Gut. Appl. Environ. Microbiol. 2000, 66, 1654-1661. [CrossRef] [PubMed]

46. Tremaroli, V.; Bäckhed, F. Functional interactions between the gut microbiota and host metabolism. Nature 2012, 489, 242-249. [CrossRef] [PubMed]

47. Sokol, H.; Pigneur, B.; Watterlot, L.; Lakhdari, O.; Bermúdez-Humarán, L.G.; Gratadoux, J.-J.; Blugeon, S.; Bridonneau, C.; Furet, J.-P.; Corthier, G.; et al. Faecalibacterium prausnitzii is an anti-inflammatory commensal bacterium identified by gut microbiota analysis of Crohn disease patients. Proc. Natl. Acad. Sci. USA 2008, 105, 16731-16736. [CrossRef] [PubMed]

48. Seksik, P.; Firmesse, O.; Nion-Larmurier, I.; Cosnes, J.; Sokol, H.; Furet, J.P.; Beaugerie, L.; Corthier, G.; Marteau, P.; Doré, J.; et al. Low counts of Faecalibacterium prausnitzii in colitis microbiota. Inflamm. Bowel Dis. 2009, 15, 1183-1189.

49. Voudoukis, E. Multipotent role of platelets in inflammatory bowel diseases: A clinical approach. WJG 2014, 20, 3180. [CrossRef] [PubMed]

50. Taniguchi, A.; Fukushima, M.; Seino, Y.; Sakai, M.; Yoshii, S.; Nagasaka, S.; Yamauchi, I.; Okumura, T.; Nin, K.; Tokuyama, K.; et al. Platelet count is independently associated with insulin resistance in non-obese Japanese type 2 diabetic patients. Metabolism 2003, 52, 1246-1249. [CrossRef]

51. Sterner, G.; Carlson, J.; Ekberg, G. Raised platelet levels in diabetes mellitus complicated with nephropathy. J. Intern. Med. 1998, 244, 437-441. [CrossRef]

52. Furet, J.-P.; Kong, L.-C.; Tap, J.; Poitou, C.; Basdevant, A.; Bouillot, J.-L.; Mariat, D.; Corthier, G.; Doré, J.; Henegar, C.; et al. Differential Adaptation of Human Gut Microbiota to Bariatric Surgery-Induced Weight Loss: Links with Metabolic and Low-Grade Inflammation Markers. Diabetes 2010, 59, 3049-3057. [CrossRef]

53. Käser, A. Interleukin-6 stimulates thrombopoiesis through thrombopoietin: Role in inflammatory thrombocytosis. Blood 2001, 98, 2720-2725. [CrossRef] [PubMed]

54. Huang, X.-L. Faecalibacterium prausnitzii supernatant ameliorates dextran sulfate sodium induced colitis by regulating Th17 cell differentiation. WJG 2016, 22, 5201. [CrossRef]

55. The Human Microbiome Project Consortium; Huttenhower, C.; Gevers, D.; Knight, R.; Abubucker, S.; Badger, J.H.; Chinwalla, A.T.; Creasy, H.H.; Earl, A.M.; Fitzgerald, M.G.; et al. Structure, function and diversity of the healthy human microbiome. Nature 2012, 486, 207-214.

56. Lozupone, C.A.; Stombaugh, J.I.; Gordon, J.I.; Jansson, J.K.; Knight, R. Diversity, stability and resilience of the human gut microbiota. Nature 2012, 489, 220-230. [CrossRef] [PubMed]

57. Ott, S.J. Reduction in diversity of the colonic mucosa associated bacterial microflora in patients with active inflammatory bowel disease. Gut 2004, 53, 685-693. [CrossRef] [PubMed]

58. Shah, V.; Lambeth, S.M.; Carson, T.; Lowe, J.; Ramaraj, T.; Leff, J.W.; Luo, L.; Bell, C.J. Composition Diversity and Abundance of Gut Microbiome in Prediabetes and Type 2 Diabetes. J. Diabetes Obes. 2015, 2, 108-114. [CrossRef] [PubMed]

59. Wang, M.; Karlsson, C.; Olsson, C.; Adlerberth, I.; Wold, A.E.; Strachan, D.P.; Martricardi, P.M.; Åberg, N.; Perkin, M.R.; Tripodi, S.; et al. Reduced diversity in the early fecal microbiota of infants with atopic eczema. J. Allergy Clin. Immunol. Pract. 2008, 121, 129-134. [CrossRef] [PubMed]

60. Taur, Y.; Jenq, R.; Perales, M.-A.; Littmann, E.R.; Morjaria, S.; Ling, L.; No, D.; Gobourne, A.; Viale, A.; Dahi, P.; et al. The effects of intestinal tract bacterial diversity on mortality following allogeneic hematopoietic stem cell transplantation. Blood 2014, 124, 1174-1182. [CrossRef] [PubMed]

61. Malard, F.; Gasc, C.; Plantamura, E.; Dore, J. High gastrointestinal microbial diversity and clinical outcome in graft-versus-host disease patients. Bone Marrow Transplant. 2018, 53, 1493-1497. [CrossRef]

62. D’Angelo, G.; Capasso, S.; Sticco, L.; Russo, D. Glycosphingolipids: Synthesis and functions. FEBS J. 2013, 280, 6338-6353. [CrossRef] [PubMed]

63. Bremer, E.G.; Hakomori, S.; Bowen-Pope, D.F.; Raines, E.; Ross, R. Ganglioside-mediated modulation of cell growth, growth factor binding, and receptor phosphorylation. J. Biol. Chem. 1984, 259, 6818-6825. [PubMed] 
64. Yates, A.; VanBrocklyn, J.; Saqr, H.; Guan, Z.; Stokes, B.; O’Dorisio, M. Mechanisms through Which Gangliosides Inhibit PDGF-Stimulated Mitogenesis in Intact Swiss 3T3 Cells: Receptor Tyrosine Phosphorylation, Intracellular Calcium, and Receptor Binding. Exp. Cell Res. 1993, 204, 38-45. [CrossRef] [PubMed]

65. Su, R.; Li, K.; Yang, M.; Zhang, X.; Tsang, K.; Fok, T.; Li, C.; Yuen, P. Platelet-derived growth factor enhances ex vivo expansion of megakaryocytic progenitors from human cord blood. Bone Marrow Transplant. 2001, 27, 1075-1080. [CrossRef] [PubMed]

66. Pekny, M.; Gebre-Medhin, S.; Swolin, B.; Betsholtz, C.; Leveen, P.; Larsson, E. Mice deficient for PDGF B show renal, cardiovascular, and hematological abnormalities. Genes Dev. 1994, 8, 1875-1887.

67. Lev, P.R.; Marta, R.F.; Vassallu, P.; Molinas, F.C. Variation of PDGF, TGFbeta, and bFGF levels in essential thrombocythemia patients treated with anagrelide. Am. J. Hematol. 2002, 70, 85-91. [CrossRef] [PubMed]

68. Kavey, R.-E.W.; Allada, V.; Daniels, S.R.; Hayman, L.L.; McCrindle, B.W.; Newburger, J.W. Cardiovascular risk reduction in high-risk pediatric patients: A scientific statement from the American Heart Association expert panel on population and prevention science; the councils on cardiovascular disease in the young, epidemiology and prevention, nutrition, physical activity and metabolism, high blood pressure research, cardiovascular nursing, and the kidney in heart disease; and the interdisciplinary working group on quality of care and outcomes research: Endorsed by the American Academy of Pediatrics. Circulation 2006, 114, 2710-2738. [PubMed]

69. Hua, W.; Hongwei, W.; Peixuan, C. Kawasaki disease on PDGF expression and VSMC proliferation. J. Tongji Med. Univ. 1998, 18, 243-246. [CrossRef]

70. Reilly, J. Idiopathic myelofibrosis: pathogenesis, natural history and management. Blood Rev. 1997, 11, 233-242. [CrossRef]

71. Greer, J.P.; Arber, D.A.; Glader, B.; List, A.F.; Means, R.T.; Paraskevas, F.; Rodgers, G.M. Wintrobe's Clinical Hematology; Wolters Kluwer Health/Lippincott Williams \& Wilkins: Philadelphia, PA, USA, 2014.

72. Kadikoylu, G.; Yavasoglu, I.; Bolaman, Z.; Senturk, T. Platelet parameters in women with iron deficiency anemia. J. Natl. Med. Assoc. 2006, 98, 398-402.

73. Park, M.-J.; Park, P.-W.; Seo, Y.-H.; Kim, K.-H.; Park, S.-H.; Jeong, J.-H.; Ahn, J.-Y. The relationship between iron parameters and platelet parameters in women with iron deficiency anemia and thrombocytosis. Platelets 2012, 24, 348-351. [CrossRef]

74. Frelinger, A.L.; Grace, R.F.; Gerrits, A.J.; Berny-Lang, M.A.; Brown, T.; Carmichael, S.L.; Neufeld, E.J.; Michelson, A.D. Platelet function tests, independent of platelet count, are associated with bleeding severity in ITP. Blood 2015, 126, 873-879. [CrossRef] [PubMed]

(C) 2019 by the authors. Licensee MDPI, Basel, Switzerland. This article is an open access article distributed under the terms and conditions of the Creative Commons Attribution (CC BY) license (http://creativecommons.org/licenses/by/4.0/). 